Article

\title{
Thymine- and Adenine-Functionalized Polystyrene Form Self-Assembled Structures through Multiple Complementary Hydrogen Bonds
}

\author{
Yu-Shian Wu, Yi-Chen Wu and Shiao-Wei Kuo * \\ Department of Materials and Optoelectronic Science, Center for Functional Polymers and Supramolecular \\ Materials, National Sun Yat-Sen University, Kaohsiung 80424, Taiwan; \\ E-Mails: m023100010@student.nsysu.edu.tw (Y.-S.W.); m973100014@student.nsysu.edu.tw (Y.-C.W.) \\ * Author to whom correspondence should be addressed; E-Mail: kuosw@faculty.nsysu.edu.tw; \\ Tel./Fax: +886-752-540-99.
}

Received: 22 May 2014; in revised form: 6 June 2014 / Accepted: 9 June 2014 /

Published: 18 June 2014

\begin{abstract}
In this study, we investigated the self-assembly of two homopolymers of the same molecular weight, but containing complementary nucleobases. After employing nitroxide-mediated radical polymerization to synthesize poly(vinylbenzyl chloride), we converted the polymer into poly(vinylbenzyl azide) through a reaction with $\mathrm{NaN}_{3}$ and then performed click chemistry with propargyl thymine and propargyl adenine to yield the homopolymers, poly(vinylbenzyl triazolylmethyl methylthymine) (PVBT) and poly(vinylbenzyl triazolylmethyl methyladenine) (PVBA), respectively. This PVBT/PVBA blend system exhibited a single glass transition temperature over the entire range of compositions, indicative of a miscible phase arising from the formation of multiple strong complementary hydrogen bonds between the thymine and adenine groups of PVBT and PVBA, respectively; Fourier transform infrared and ${ }^{1} \mathrm{H}$ nuclear magnetic resonance spectroscopy confirmed the presence of these noncovalent interactions. In addition, dynamic rheology, dynamic light scattering and transmission electron microscopy provided evidence for the formation of supramolecular network structures in these binary PVBT/PVBA blend systems.
\end{abstract}

Keywords: miscibility; multiple hydrogen bonding; self-assembly structure; polymer complex 


\section{Introduction}

Miscible polymer blends featuring strong hydrogen bonding interactions are of interest to materials scientists, because they can exhibit improved or modified properties relative to those of their individual constituent polymers [1-3]. The strength and extent of hydrogen bonding in copolymer or polymer blends depend on the respective affinities [4-6] of their hydrogen bond donors and acceptors. Polymer blend systems based on poly(vinyl phenol)/poly(4-vinyl pyridine) ( $\mathrm{PVPh} / \mathrm{P} 4 \mathrm{VP})$ and poly(vinyl phenol)/poly(vinyl pyrrolidone) (PVPh/PVP), which have been classified as strong hydrogen bonding systems (inter-association equilibrium constants $\left(K_{\mathrm{A}}\right)$ of 1200 and 6000 , respectively), have been studied widely [7-15]. Nevertheless, such single-site hydrogen bonds have been considered as relative weak intermolecular interactions in recent years [16-20].

There is much interest in supramolecular structures based on complementary multiple-hydrogen-bond arrays prepared from synthetic polymers presenting nucleotide bases on their side chains [21-34]. The binding forces in systems featuring multiple hydrogen bonds can be tuned, leading to inter-association equilibrium constants $\left(K_{\mathrm{A}}\right)$ ranging from several hundred up to more than $10^{6}$ [21-34]. The most important arrays of multiple hydrogen bonding interactions are those found in complex biological systems, for example, DNA, a very influential structure in polymer science that is often presented as a defined macromolecule possessing a nearly perfect molecular structure. The preparation of synthetic polymers that mimic DNA remains a great challenge in polymer science [35]. The self-assembly of pairs of DNA strands is mediated by intermolecular hydrogen bonding between complementary purine (adenine $(A)$, guanine $(\mathrm{G})$ ) and pyrimidine (thymine $(\mathrm{T})$, cytosine $(\mathrm{C})$ ) bases attached to a phosphate sugar backbone, with $\mathrm{G}$ binding selectively to $\mathrm{C}$ and A binding selectively to $\mathrm{T}$ [36].

Lutz et al. reported an A-functionalized copolymer that self-assembled with its T-functionalized counterpart into supramolecular aggregates that displayed temperature-dependent "melting" behavior in nonpolar solvents [37-39]. Long et al. used nitroxide-mediated radical polymerization (NMRP) to synthesize a nucleobase-functionalized triblock copolymer featuring A- and T-containing blocks; the blending of complementary polymers led to dramatic increases in the viscosity and glass transition temperature $\left(T_{\mathrm{g}}\right)$ as a result of hydrogen bonding interactions between the A and T units [40]. We have also investigated the miscibility behavior, specific interactions and supramolecular structures of blends of the DNA-like copolymers, poly(vinylbenzylthymine-co-butyl methacrylate) (T-PBMA) and poly(vinylbenzyladenine-co-styrene) (A-PS), with respect to their vinylbenzylthymine (VBT) and vinylbenzyladenine (VBA) contents during free radical copolymerization [21-24]. We also examined the strong multiple hydrogen bonding interactions between the 2,4-diaminotriazine (DAT) groups in poly(2-vinyl-4,6-diamino-1,3,5-triazine-co-methyl methacrylate) (PVDAT-co-PMMA) and the $\mathrm{T}$ groups of the VBT units in poly(vinylbenzyl thymine-co-methyl methacrylate) (PVBT-co-PMMA). Notably, blending only $12 \mathrm{~mol} \%$ of VBT and $20 \mathrm{~mol} \%$ of VDAT into the PMMA copolymer chain increased the value of $T_{\mathrm{g}}$ by $50{ }^{\circ} \mathrm{C}$ relative to that of pure PMMA. Unfortunately, the use of free radical copolymerization to prepare highly $\mathrm{T}$ - and A-functionalized vinylbenzyl monomers is difficult (leading to only $7 \%-24 \%$ functionalization) [21-24], because of the significantly different polarities of the heteronucleobase monomers with respect to styrene or methacrylate monomers [41]. Indeed, all highly T-functionalized copolymers have been prepared through the chemical modification of the side chain groups of the copolymer chain, not directly through free radical copolymerization. 
Overberger et al. reported poly(L-lysine) derivatives functionalized with various nucleic acids (T, A, uracil), reaching 8-93 mol \% base contents [42]. Free radical polymerization can be used, however, to prepare polyacrylate, polymethacrylate and PMMA derivatives presenting T functionalities (4-100 mol \%), starting from various T-functionalized acrylate monomers [43]. Cheng et al. prepared a series of nucleobase homopolymers through atom transfer radical polymerization (ATRP) of VBT and VBA, but obtained relative low and inconsistent molecular weights for these two homopolymers [44].

In this study, we used a combination of NMRP and click chemistry to prepare high-performance polymers featuring high contents of heteronucleobases. First, we employed NMRP to synthesize a poly(vinylbenzyl chloride) (PVBC) homopolymer and then converted it to the corresponding poly(vinylbenzyl azide) $\left(\mathrm{PVBN}_{3}\right)$ homopolymer through reactions with $\mathrm{NaN}_{3}$ [26]. Finally, we used click chemistry to react $\mathrm{PVBN}_{3}$ with propargyl thymine (PT) and propargyl adenine (PA) to yield poly(vinylbenzyl triazolylmethyl methylthymine) (PVBT) and poly(vinylbenzyl triazolylmethyl methyladenine) (PVBA) homopolymers, respectively (Scheme 1). Using this approach ensured that the degrees of polymerization of PVBT and PVBT were identical, because we prepared them from the same $\mathrm{PVBN}_{3}$ homopolymer. To the best of our knowledge, polymer blend systems derived from binary homopolymers having exactly the same degree of polymerization and stabilized through hydrogen bonding interactions have never been reported previously. We have used differential scanning calorimetry (DSC), Fourier transform infrared (FTIR) spectroscopy, ${ }^{1} \mathrm{H}$ nuclear magnetic resonance (NMR) spectroscopy, dynamic rheology, dynamic light scattering and transmission electron microscopy (TEM) to investigate the thermal, rheological properties and supramolecular structures of these binary PVBT/PVBA blend complexes stabilized through strong complementary multiple hydrogen bonds (Scheme 1).

Scheme 1. Syntheses of (a) poly(vinylbenzyl chloride) (PVBC)-2,2,6,6-tetramethyl-1piperidinyloxy (TEMPO); (b) poly(vinylbenzyl azide) $\left(\mathrm{PVBN}_{3}\right)$; (c) poly(vinylbenzyl triazolylmethyl methylthymine) (PVBT); (d) poly(vinylbenzyl triazolylmethyl methyladenine) (PVBA); and (e) PVBT/PVBA complexes featuring multiple hydrogen bonding interactions.

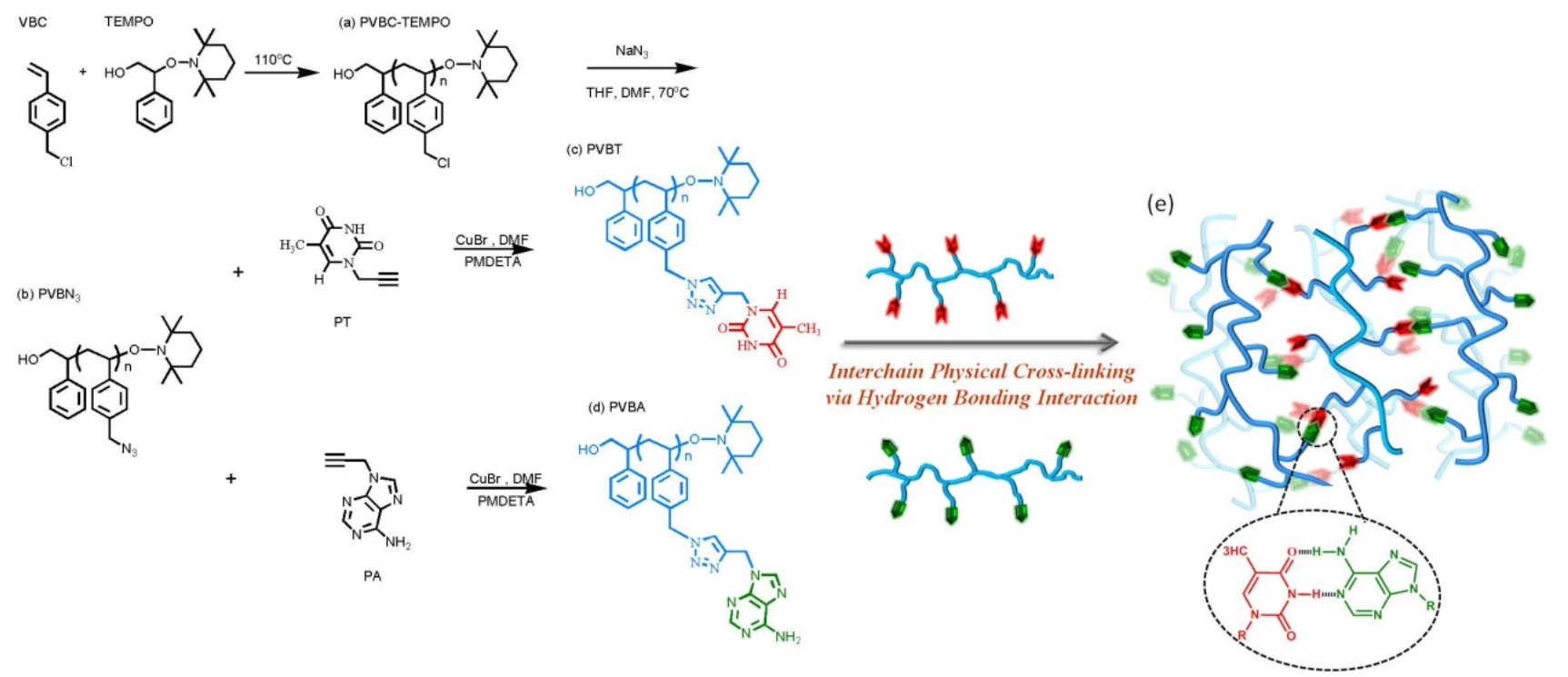




\section{Experimental Section}

\subsection{Materials}

Benzoyl peroxide, 2,2,6,6-tetramethyl-1-piperidinyloxy (TEMPO), styrene and 4-vinylbenzyl chloride (VBC), were obtained from Aldrich (St. Louis, MO, USA); they were passed through an alumina column and then vacuum-distilled from $\mathrm{CaH}_{2}$ under reduced pressure prior to use. Sodium azide $\left(\mathrm{NaN}_{3}\right)$, copper(I) bromide $(\mathrm{CuBr}, 98 \%)$ and $N, N, N^{\prime}, N^{\prime \prime}, N^{\prime \prime \prime}$-pentamethyldiethylenetriamine (PMDETA, 99\%) were also purchased from Aldrich. Thymine, adenine and $\mathrm{K}_{2} \mathrm{CO}_{3}$ were purchased from Showa Chemical (Tokyo, Japan). Propargyl bromide ( $80 \%$ in toluene, stabilized with $\mathrm{MgO}$ ) was purchased from Showa Chemical. Dimethylformamide (DMF) was distilled from $\mathrm{CaH}_{2}$ under vacuum prior to use. 1-Hydroxy-2-phenyl-2-(2',2',6',6'-tetramethyl-1-piperidinyloxy)ethane (TEMPO-OH) was synthesized as described previously [26,45]. All other chemicals were of reagent grade and used as received without further purification.

\subsection{Poly(vinylbenzyl azide) $\left(P V B N_{3}\right)$}

The purified VBC $(8 \mathrm{~mL})$ and TEMPO-OH $(0.38 \mathrm{~g})$ were placed in a $50-\mathrm{mL}$ three-neck flask. The orange reactant solution was heated at $120^{\circ} \mathrm{C}$ for several hours; the crude PVBC sample was purified through repeated precipitations from $\mathrm{CH}_{2} \mathrm{Cl}_{2}$ into $\mathrm{MeOH}\left(M_{\mathrm{n}}=15,600 \mathrm{~g} \cdot \mathrm{mol}^{-1}\right.$, polydispersity $(\mathrm{PDI})=1.12) \cdot \mathrm{NaN}_{3}(5 \mathrm{~g})$ was added to a solution of PVBC $(3 \mathrm{~g})$ in DMF $(90 \mathrm{~mL})$, and then, the reaction mixture was stirred at room temperature overnight. After precipitation into water, the product was dissolved in $\mathrm{CH}_{2} \mathrm{Cl}_{2}$ and precipitated in $\mathrm{MeOH}$. The resulting solid was filtered off and dried in a vacuum oven for $24 \mathrm{~h}$.

\subsection{Propargyl-Adenine (PA) [46]}

A mixture of $\mathrm{A}(5 \mathrm{~g})$ and $\mathrm{K}_{2} \mathrm{CO}_{3}(7.7 \mathrm{~g})$ in DMF $(130 \mathrm{~mL})$ was placed in a $250-\mathrm{mL}$ two-neck flask. After adding propargyl bromide $(8 \mathrm{~mL})$ dropwise to the solution, the mixture was stirred at $50{ }^{\circ} \mathrm{C}$ overnight; the precipitate was filtered off, the solvent evaporated and the crude product purified through recrystallization (twice from $\mathrm{MeOH}$ ) to obtain a pale-pink powder.

\subsection{Poly(4-vinylbenzyl triazolylmethyl methyladenine) (PVBA)}

$\mathrm{PVBN}_{3}(0.2 \mathrm{~g}), \mathrm{PA}(0.23 \mathrm{~g})$ and $\mathrm{CuBr}(0.03 \mathrm{~g})$ were dissolved in DMF (40 mL) in a flask equipped with a magnetic stirring bar. After one brief freeze/thaw/pump cycle, PMDETA $(0.07 \mathrm{~mL})$ was added, and then, the reaction mixture was carefully degassed through three freeze/thaw/pump cycles at $60{ }^{\circ} \mathrm{C}$ and stirred for $24 \mathrm{~h}$. After passing through a neutral alumina column to remove copper catalysts, the solvent was evaporated, the residue was stirred in $\mathrm{MeOH}$ and the resulting solid was filtered off and dried in a vacuum oven to obtain a pale-brown powder $\left(M_{\mathrm{n}}=33,200 \mathrm{~g} \cdot \mathrm{mol}^{-1}, \mathrm{PDI}=1.12\right)$.

\subsection{Propargyl-Thymine (PT) [26]}

A mixture of $\mathrm{T}(8 \mathrm{~g})$ and $\mathrm{K}_{2} \mathrm{CO}_{3}(13 \mathrm{~g})$ in DMF $(150 \mathrm{~mL})$ was placed into a 250 -mL two-neck flask. After adding propargyl bromide $(14 \mathrm{~mL})$ dropwise to the solution, the mixture was stirred at room 
temperature overnight; the precipitate was filtered off, the solvent evaporated and the residue purified through column chromatography ( $n$-hexane/EtOAc, 1:2) to obtain a pale-yellow powder.

\subsection{Poly(4-vinylbenzyl triazolylmethyl methylthymine) (PVBT)}

$\mathrm{PVBN}_{3}(0.3 \mathrm{~g})$, PT $(0.37 \mathrm{~g})$ and $\mathrm{CuBr}(0.04 \mathrm{~g})$ were dissolved in DMF (40 mL) in a flask equipped with a magnetic stirrer bar. After one brief freeze/thaw/pump cycle, PMDETA $(0.1 \mathrm{~mL})$ was added, and then, the reaction mixture was carefully degassed through three freeze/thaw/pump cycles at $60{ }^{\circ} \mathrm{C}$ and stirred for $24 \mathrm{~h}$. After passing through a neutral alumina column to remove copper catalysts, the mixture was precipitated in $\mathrm{MeOH}$, and the resulting solid was filtered off and dried in a vacuum oven for $24 \mathrm{~h}\left(M_{\mathrm{n}}=32,400 \mathrm{~g} \cdot \mathrm{mol}^{-1}\right.$, PDI $\left.=1.12\right)$.

\subsection{PVBT/PVBA Blend Complexes}

Blend samples containing various weight fractions of PVBA and PVBT were prepared by dissolving $10 \mathrm{mg}$ of the blend in DMF, stirring the solution for $24 \mathrm{~h}$ and then evaporating the solvent slowly at $40{ }^{\circ} \mathrm{C}$ in a vacuum oven over $24 \mathrm{~h}$.

\subsection{Complex Solutions}

To prepare complex solutions, individual solutions of PVBA and PVBT in DMF were mixed dropwise, very slowly, one with the other; the total concentration was $2 \mathrm{mg}$ in $2 \mathrm{~mL}$. For rheological studies, a DMF solution containing $8 \mathrm{wt} \%(0.12 \mathrm{~g} / 1.5 \mathrm{~mL})$ of the blend complex was stirred for $24 \mathrm{~h}$.

\subsection{Characterization}

${ }^{1} \mathrm{H}$ NMR spectra were recorded from solutions in $\mathrm{CDCl}_{3}$ and $d_{6}$-dimethyl sulfoxide (DMSO) using a Varian Unity Inova (McKinley Scientific, Sparta, NJ, USA) 500 FT NMR spectrometer operated at $500 \mathrm{MHz}$; chemical shifts are reported in parts per million (ppm). Molecular weights and molecular weight distributions were determined at $80{ }^{\circ} \mathrm{C}$ through gel permeation chromatography (GPC) using a Waters 510 high performance liquid chromatography (HPLC) (Milford, MA, USA) equipped with a 410 differential refractometer, a UV detector and three Ultrastyragel columns (100, $500 \AA$ and $103 \AA$ ) connected in series; DMF was the eluent; the flow rate was $0.6 \mathrm{~mL} \mathrm{~min}{ }^{-1}$. The molecular weight calibration curve was obtained using PS standards. FTIR spectra of the polymer blend films were recorded using the conventional KBr disk method with a Bruker Tensor (Billerica, MA, USA) 27 FTIR spectrophotometer ( 32 scans; spectral resolution: $1 \mathrm{~cm}^{-1}$ ); the films were sufficiently thin to obey the Beer-Lambert law. The thermal properties of the PVBA/PVBT blend films were determined through DSC analysis using a TA Q-20 instrument (TA Instrument, New Castle, DE, USA); the scan rate was $20{ }^{\circ} \mathrm{C} \min ^{-1}$ within the temperature range from $-50{ }^{\circ} \mathrm{C}$ to $+250{ }^{\circ} \mathrm{C}$ under a $\mathrm{N}_{2}$ atmosphere. The glass transition temperature $\left(T_{\mathrm{g}}\right)$ is defined herein as the midpoint of the heat capacity transition between the upper and lower points of deviation from the extrapolated liquid and glass lines. TEM was performed using a JEOL 2100 microscope (JEOL Ltd., Tokyo, Japan) operated at $200 \mathrm{kV}$. The complexes were placed onto copper grids coated with carbon-supporting films, followed by staining through exposure to $\mathrm{I}_{2}$ vapor (to detect the PVBA/PVBT complexes). $\mathrm{I}_{2}$ is a preferential staining agent for $\mathrm{T}$ and A units. 
The hydrodynamic diameters of the complexes were measured through dynamic light scattering (DLS) using a Brookhaven 90 plus model apparatus (Brookhaven Instruments, Holtsville, NY, USA) and a He-Ne laser operated at a power of $35 \mathrm{~mW}$ at $632.8 \mathrm{~nm}$. All samples were measured 10 times at $25{ }^{\circ} \mathrm{C}$ with 90 angles of detection. The experimental correlation function was analyzed using the cumulant method and the CONTIN algorithm. The Stokes-Einstein approximation was used to convert the diffusion coefficient into the form of the hydrodynamic diameter $\left(D_{\mathrm{h}}\right)$. The apparent viscosities of the samples were obtained using an Anton Paar Physioa MCR 301 Rheometer (Graz, Austria) at $25^{\circ} \mathrm{C}$, with the angular frequency $(x)$ varied from $100 \mathrm{~s}^{-1}$ to $0.01 \mathrm{~s}^{-1}$.

\section{Results and Discussion}

\subsection{Synthesis of PVBA and PVBT}

We added TEMPO-OH as the initiator for the thermal bulk polymerization of the highly reactive VBC monomer at elevated temperature. Figure 1a presents the ${ }^{1} \mathrm{H}$ NMR spectrum of PVBC in $\mathrm{CDCl}_{3}$. The signals for the styrene-derived aromatic protons appear at $7.2 \mathrm{ppm}$ and $6.2-6.8 \mathrm{ppm}$. The signal near 0.9 ppm originated from the tetramethyl protons of the TEMPO-OH initiator; this signal has been reported to appear in the range $0.1-1.3 \mathrm{ppm}$ as several peaks with variable intensities, due to conformational inversion involving ring conversion; herein, we used only the peak at $0.9 \mathrm{ppm}$ to indicate the attachment of the TEMPO unit [45].

Figure 1. ${ }^{1} \mathrm{H}$ NMR spectra of (a) $\mathrm{PVBC}$ in $\mathrm{CDCl}_{3}$; (b) $\mathrm{PVBN}_{3}$ in $\mathrm{CDCl}_{3}$; (c) $\mathrm{PVBA}$ in $d_{6}$-DMSO; and (d) PA in $\mathrm{CDCl}_{3}$.<smiles>CC#Cn1cnc2c(N)ncnc21</smiles>

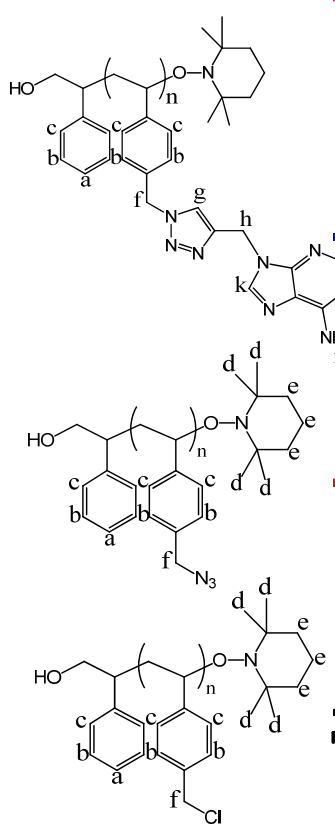

(d) PA

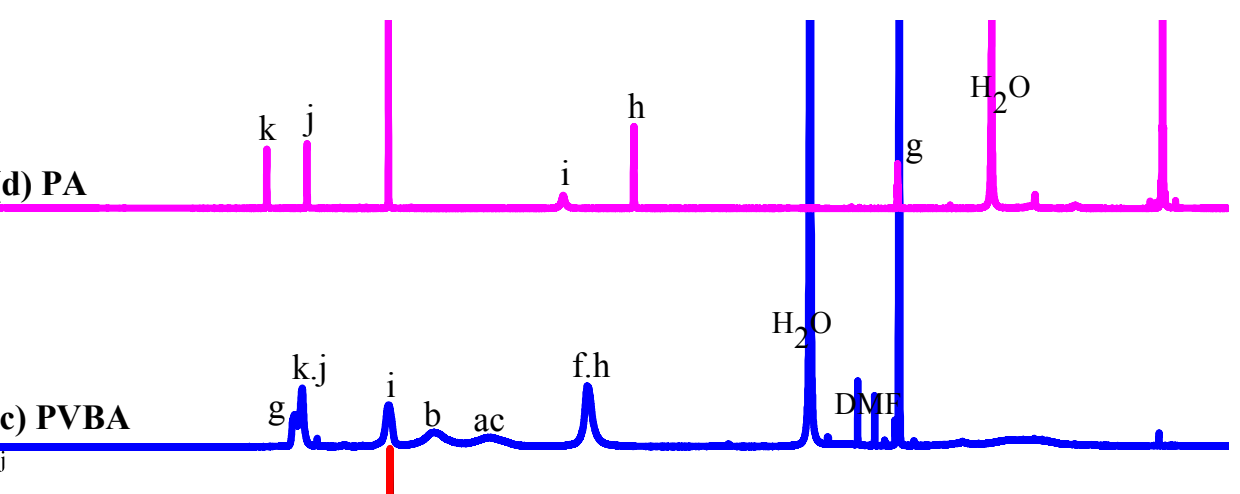

(b) $\mathrm{PVBN}_{3}$

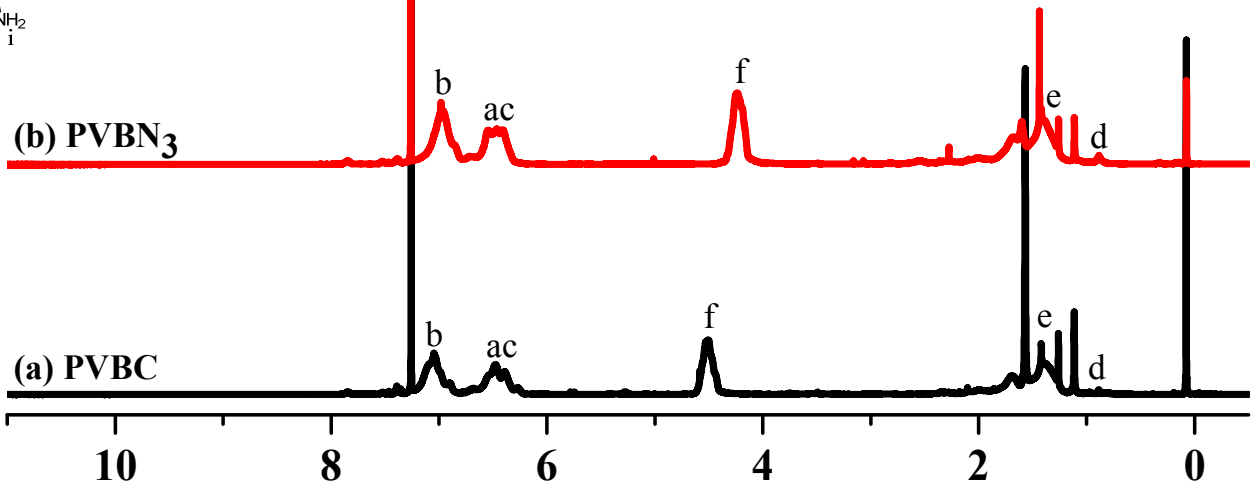

${ }^{1} \mathrm{H}$ Chemical shift (ppm) 
In addition, a signal for the chloromethyl units $(4.5 \mathrm{ppm})$ indicated the successful synthesis of the PVBC homopolymer. Similarly, a signal for the chloromethyl units $\left(\mathrm{CH}_{2} \mathrm{Cl}\right)$ of the PVBC homopolymer appeared at $46.38 \mathrm{ppm}$ in the ${ }^{13} \mathrm{C}$ NMR spectrum, Figure 2a, providing additional evidence for its formation. Figure $1 \mathrm{~b}$ presents the ${ }^{1} \mathrm{H}$ spectrum of $\mathrm{PVBN}_{3}$ in $\mathrm{CDCl}_{3}$. The signal of the benzylic methylene groups shifted upfield significantly from $4.5 \mathrm{ppm}$ for PVBC $\left(\mathrm{CH}_{2} \mathrm{Cl}\right)$ to $4.2 \mathrm{ppm}$ for $\mathrm{PVBN}_{3}\left(\mathrm{CH}_{2} \mathrm{~N}_{3}\right)$. The absence of a resonance at $4.5 \mathrm{ppm}$ suggested that the substitution reactions had occurred to completion, as confirmed in the ${ }^{13} \mathrm{C}$ NMR spectrum of $\mathrm{PVBN}_{3}$ Figure $2 b$, in which the signal of the benzylic methylene units shifted downfield to $54.3 \mathrm{ppm}$ for $\mathrm{PVBN}_{3}\left(\mathrm{CH}_{2} \mathrm{~N}_{3}\right)$ from $46.3 \mathrm{ppm}$ for PVBC $\left(\mathrm{CH}_{2} \mathrm{Cl}\right)$, and in its FTIR spectrum, Figure 3b, which featured a characteristic signal for azido groups at $2105 \mathrm{~cm}^{-1}$. We synthesized the PVBA homopolymer through a room-temperature click reaction of a vigorously stirred, concentrated solution of the azide-functionalized $\mathrm{PVBN}_{3}$ homopolymer and $\mathrm{PA}$ in DMF containing $\mathrm{CuBr}$ and PMDETA. After performing the azide/alkyne cycloadditions, the signal of the benzylic methylene groups of $\mathrm{PVBN}_{3}$ $\left(\mathrm{CH}_{2} \mathrm{~N}_{3}, 4.23 \mathrm{ppm}\left(\mathrm{CDCl}_{3}\right)\right.$, Figure $\left.1 \mathrm{~b}\right)$ shifted downfield significantly to $5.40 \mathrm{ppm}$ for PVBA in $d_{6}$-DMSO (Figure 1c). In addition, the signal for the propargylic $\mathrm{CH}_{2}$ group of PA $(5.00 \mathrm{ppm}$ in $\mathrm{CDCl}_{3}$ ) also shifted downfield to $5.40 \mathrm{ppm}$ for the corresponding protons of PVBA in $d_{6}$-DMF, with a signal for the $\mathrm{CH}$ groups of the triazole units appearing at $8.13 \mathrm{ppm}$, confirming the successful synthesis of PVBA. Figure 1 summarizes all of the other peak assignments. We also used ${ }^{13} \mathrm{C}$ NMR spectroscopy to characterize the product of the click reaction (Figure 2). The signal for the benzylic $\mathrm{CH}_{2}$ groups of $\mathrm{PVBN}_{3}$ at $54.6 \mathrm{ppm}$ (Figure 2b) shifted to $52.05 \mathrm{ppm}$ for PVBA (Figure 2c). The signals of the alkyne carbon atoms of PA $(74.8 \mathrm{ppm}$ and $76.0 \mathrm{ppm})$ were absent in the spectrum of PVBA (Figure 2c), but two new peaks appeared at $123.6 \mathrm{ppm}$ and $140.6 \mathrm{ppm}$ (Figure 2c), representing the carbon atoms of the triazole units, confirming the successful synthesis of PVBA. Figure 2 summarizes all of the other peak assignments. FTIR spectroscopic analysis (Figure 3) confirmed the complete disappearance of the characteristic signals for the azido and acetylene groups. The signal at $2105 \mathrm{~cm}^{-1}$, corresponding to the absorbance of the azido group of $\mathrm{PVBN}_{3}$, was absent in the spectrum of PVBA; the absorption band of the NH groups of the PA units appeared at $3200-3400 \mathrm{~cm}^{-1}$ in the spectrum of PVBA, indicating that the azido and acetylene functionalities had participated in the click reactions. Taken together, the ${ }^{1} \mathrm{H}$ and ${ }^{13} \mathrm{C}$ NMR and FTIR spectra confirmed the successful synthesis of the PVBA homopolymer.

Similarly, we prepared the PVBT homopolymer through a combination of NMRP and click chemistry; Figures 4-6 display this, corresponding to the ${ }^{1} \mathrm{H}$ and ${ }^{13} \mathrm{C}$ NMR and FTIR spectra, respectively. Figure $4 \mathrm{~b}$ reveals that the signal of the benzylic $\mathrm{CH}_{2}$ groups of $\mathrm{PVBN}_{3}$ connected to the azide units shifted downfield significantly from $4.23 \mathrm{ppm}$ in $\mathrm{CDCl}_{3}$ to $5.45 \mathrm{ppm}$ in $d_{6}$-DMSO after cycloadditions to form PVBT (Figure 4c). In addition, the resonance of the propargylic $\mathrm{CH}_{2}$ group of PT also shifted downfield from $4.56 \mathrm{ppm}$ in $\mathrm{CDCl}_{3}$ to $4.88 \mathrm{ppm}$ for the corresponding protons of PVBT in $d_{6}$-DMSO, with the $\mathrm{CH}$ groups of the triazole units represented by a signal at $7.53 \mathrm{ppm}$, confirming the successful synthesis of PVBT. We also characterized this click reaction product from ${ }^{13} \mathrm{C}$ NMR spectra (Figure 5). The signal of the benzylic $\mathrm{CH}_{2}$ groups of $\mathrm{PVBN}_{3}$ at $54.6 \mathrm{ppm}$ (Figure 5b) shifted to $52.67 \mathrm{ppm}$ for PVBT (Figure 5c). The signals of the alkyne carbon atoms of PT (at $74.8 \mathrm{ppm}$ and $76.0 \mathrm{ppm}$ ) were absent in the spectrum of PVBT (Figure 5d), but two new peaks appeared at $124.0 \mathrm{ppm}$ and $142.6 \mathrm{ppm}$ in Figure 5c, representing the carbon atoms of the triazole units, confirming 
the successful synthesis of PVBT. The signals of the $\mathrm{C}=\mathrm{O}$ groups $\left(\mathrm{N} \underline{\mathrm{CONH}}, \mathrm{NHCOCCH}_{3}\right)$ of the $\mathrm{T}$ moieties appeared at $162.25 \mathrm{ppm}$ and $164.54 \mathrm{ppm}$, again consistent with the successful synthesis of PVBT. FTIR spectroscopic analysis (Figure 6) revealed the complete disappearance of the characteristic signals for the azido and acetylene groups. The signal at $2105 \mathrm{~cm}^{-1}$, corresponding to the absorbance of the azido groups of $\mathrm{PVBN}_{3}$, was absent in the spectrum of PVBT; the absorption band of the $\mathrm{C}=\mathrm{O}$ groups of PT appeared at $1690 \mathrm{~cm}^{-1}$ in the spectrum of the PVBT homopolymer, indicating that the azido and acetylene functionalities had participated in click reactions.

Figure 2. ${ }^{13} \mathrm{C}$ NMR spectra of (a) $\mathrm{PVBC}$ in $\mathrm{CDCl}_{3}$; (b) $\mathrm{PVBN}_{3}$ in $\mathrm{CDCl}_{3}$; (c) $\mathrm{PVBA}$ in $d_{6}$-DMSO; and (d) PA in $\mathrm{CDCl}_{3}$.

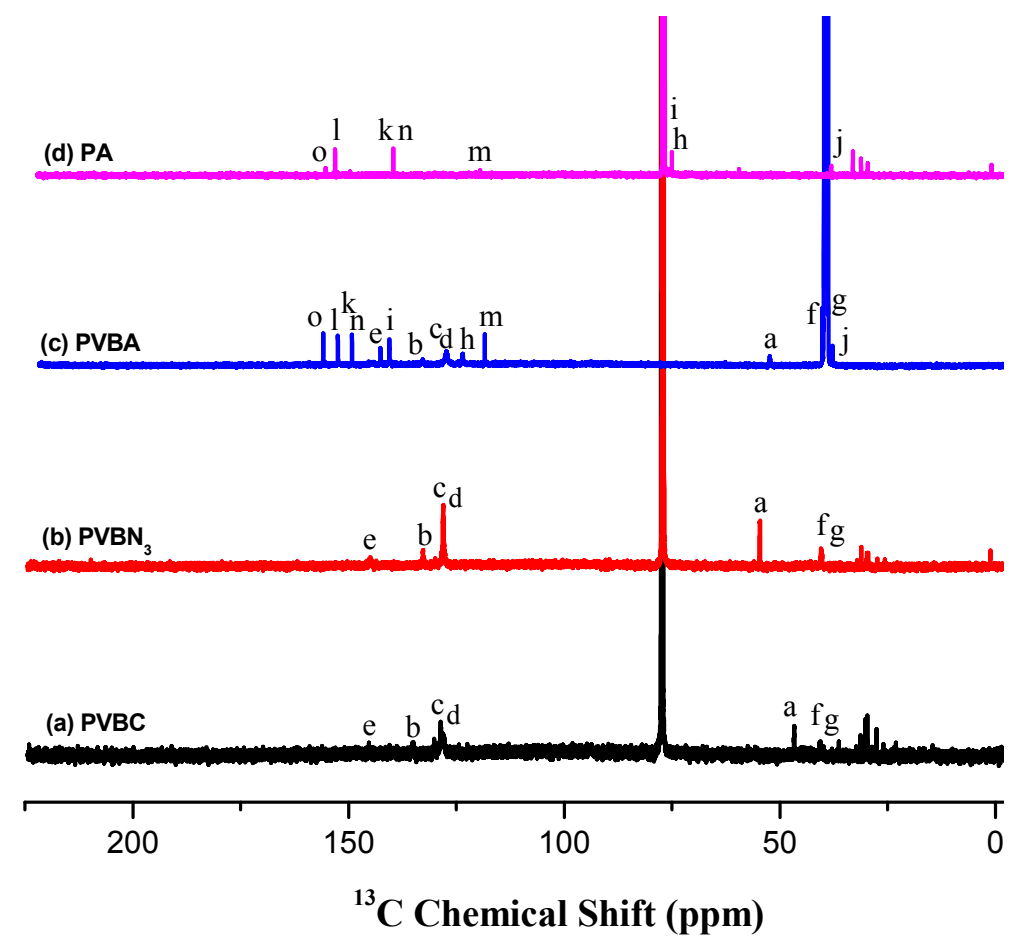

Figure 3. FTIR spectra of (a) PVBC; (b) PVBN 3 ; (c) PVBA; and (d) PA in $\mathrm{CDCl}_{3}$.

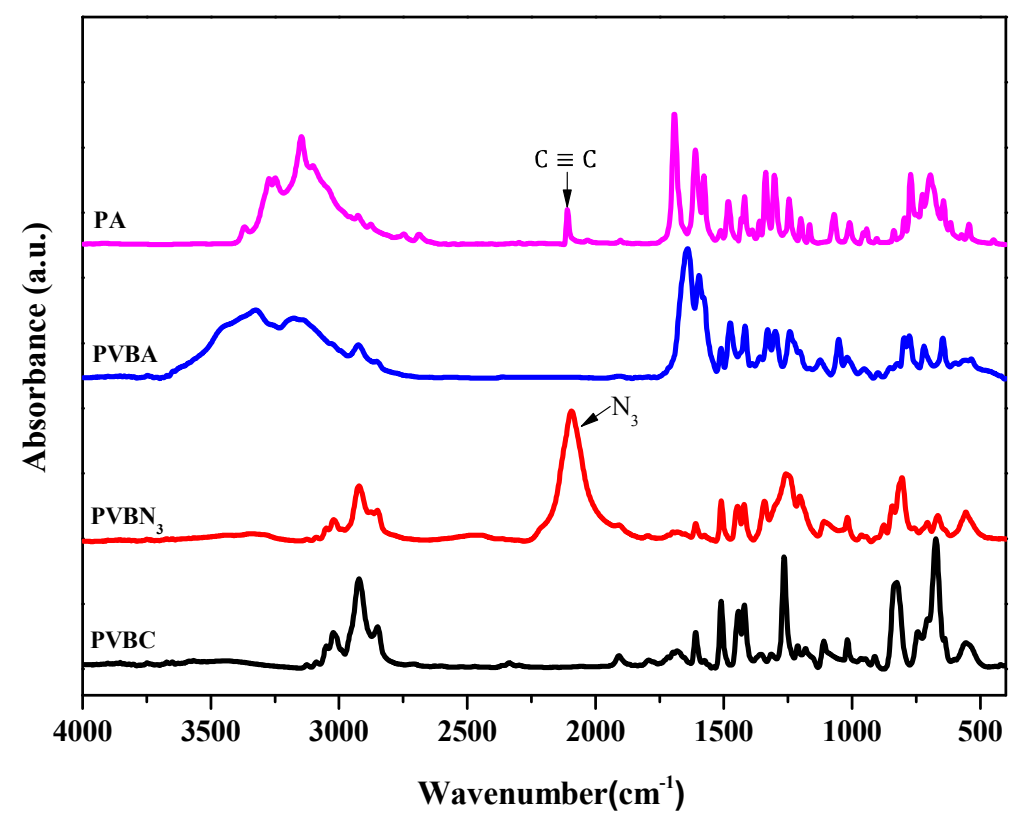


Figure 4. ${ }^{1} \mathrm{H}$ NMR spectra of (a) $\mathrm{PVBC}$ in $\mathrm{CDCl}_{3}$; (b) $\mathrm{PVBN}_{3}$ in $\mathrm{CDCl}_{3}$; (c) $\mathrm{PVBT}$ in $d_{6}$-DMSO; and (d) PT in $\mathrm{CDCl}_{3}$.

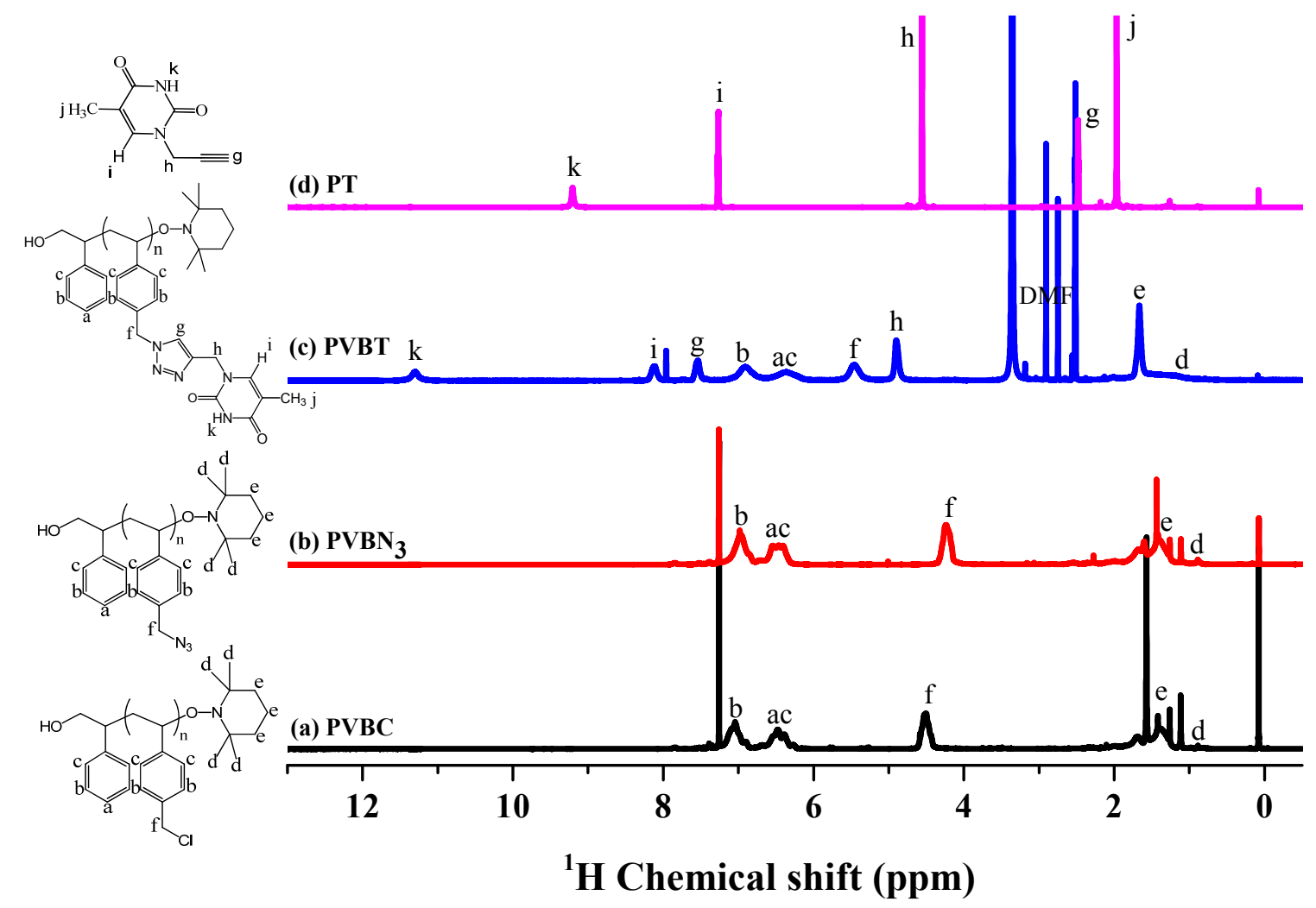

Figure 5. ${ }^{13} \mathrm{C}$ NMR spectra of (a) $\mathrm{PVBC}$ in $\mathrm{CDCl}_{3}$; (b) $\mathrm{PVBN}_{3}$ in $\mathrm{CDCl}_{3}$; (c) $\mathrm{PVBT}$ in $d_{6}$-DMSO; and (d) PT in $\mathrm{CDCl}_{3}$.

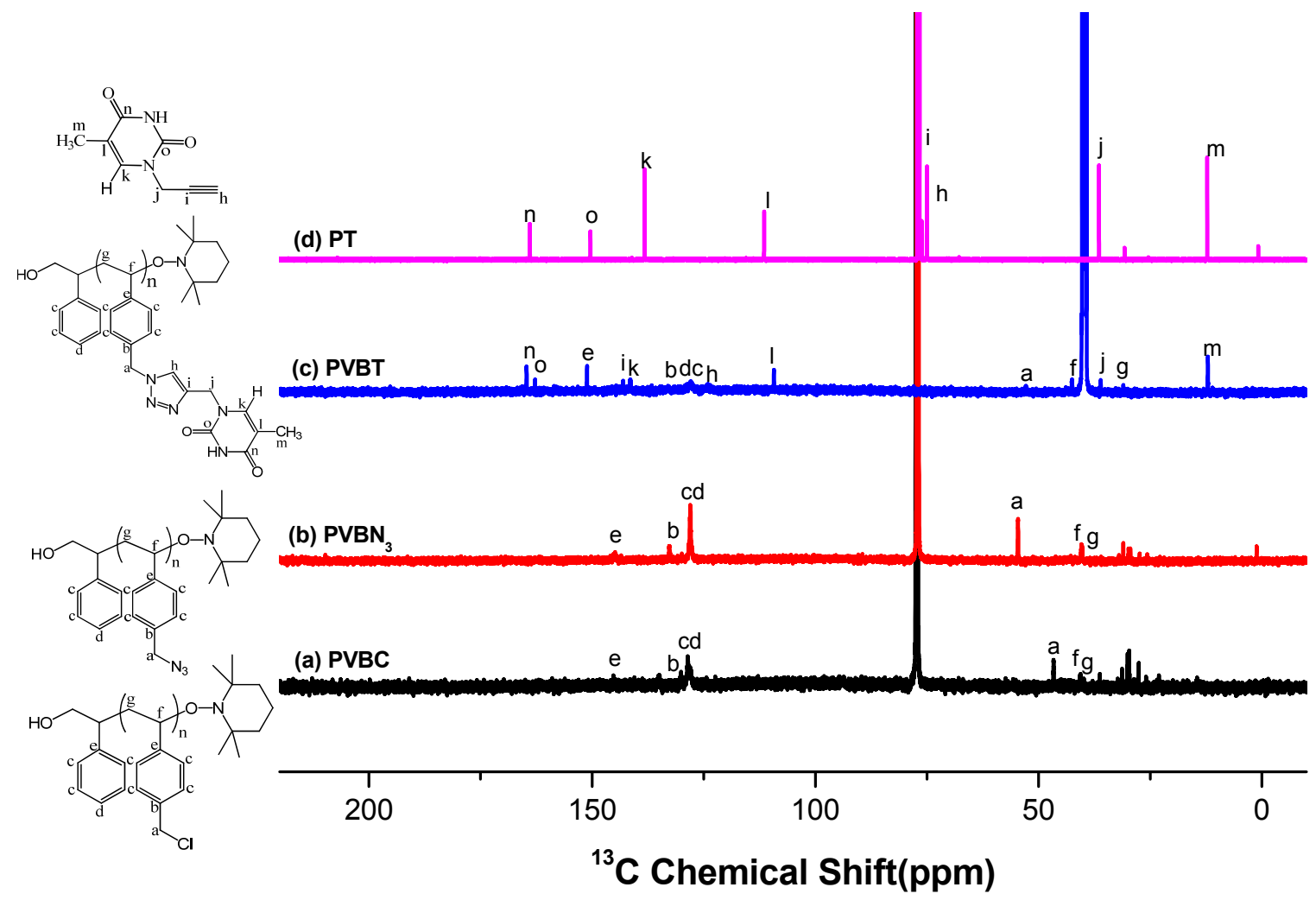


Figure 6. FTIR spectra of (a) PVBC; (b) $\mathrm{PVBN}_{3}$; (c) PVBT; and (d) PT in $\mathrm{CDCl}_{3}$.

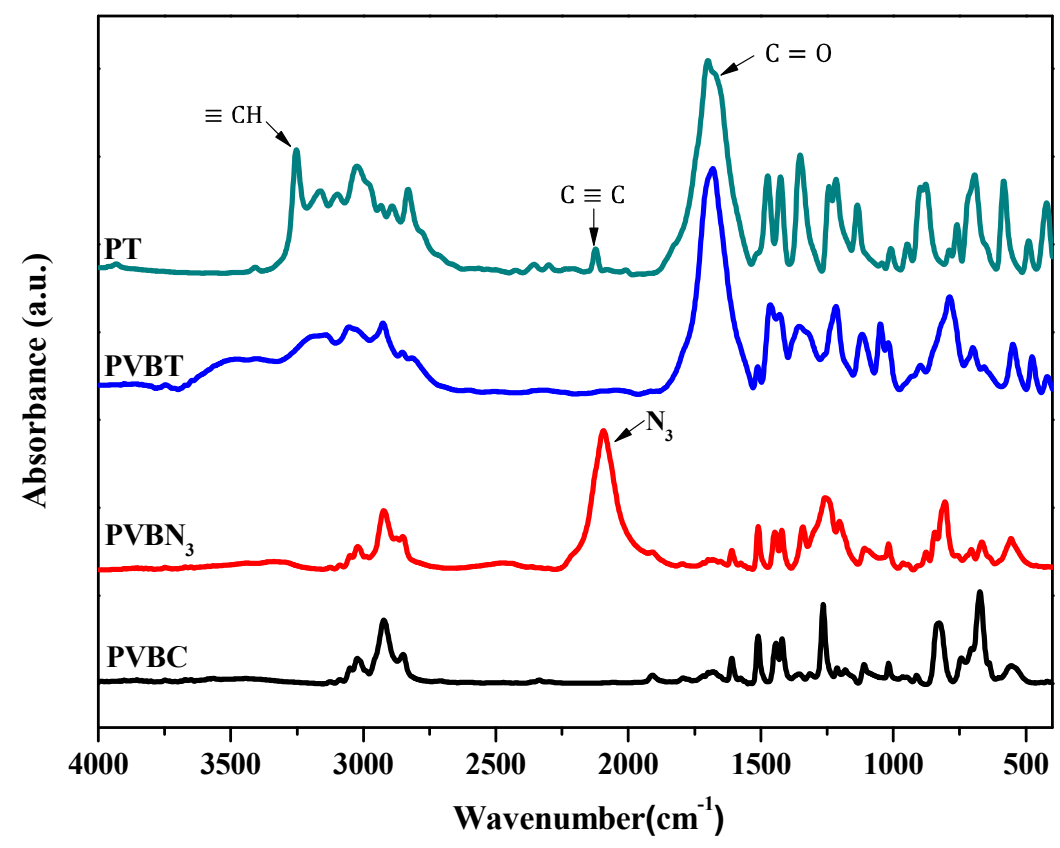

\subsection{Thermal Analyses of PVBT/PVBA Blend Complexes}

DSC analysis is a convenient method for determining miscibility in polymer blends. Figure 7a displays DSC thermograms of PVBT/PVBA blends of various compositions; we observe that all of these blends featured only a single glass transition temperature, which generally suggests the presence of fully miscible blends with a homogeneous amorphous phase. Meanwhile, each single value of $T_{\mathrm{g}}$ was higher than that of either individual polymer. The large positive deviation in these values indicates that strong interactions existed between the two polymers. Over the years, a number of equations have been offered to predict variations in the glass transition temperatures of miscible blends as a function of their composition. The most popular is the Kwei equation [47]:

$$
T_{\mathrm{g}}=\frac{W_{1} T_{\mathrm{g} 1}+k W_{2} T_{\mathrm{g} 2}}{W_{1}+k W_{2}}+q W_{1} W_{2}
$$

where $W_{1}$ and $W_{2}$ are the weight fractions of the components, $T_{\mathrm{g} 1}$ and $T_{\mathrm{g} 2}$ represent the corresponding glass transition temperatures and $k$ and $q$ are fitting constants. Figure $7 \mathrm{~b}$ displays the dependence of the value of $T_{\mathrm{g}}$ on the composition of our miscible PVBT/PVBA blends; the maximum deviation and the highest value of $T_{\mathrm{g}}$ were those obtained for the blend PVBT/PVBA $=50 / 50$. Compared with the glass transition temperature of pure PVBT $\left(167^{\circ} \mathrm{C}\right)$, that of PVBT/PVBA $=50 / 50$ had increased by $14{ }^{\circ} \mathrm{C}$. The supramolecular structures of PVBT/PVBA complexes presumably featured a hydrogen bond-induced physical crosslinking (Scheme 1). In addition, we obtained values of $k$ and $q$ of one and 35, respectively, from nonlinear least-squares "best fit" analyses. The parameter $q$ represents the strength of hydrogen bonding in the blend, reflecting a balance between the breaking of self-association and the forming of inter-association hydrogen bonds. In this study, we obtained a positive value of $q$ of 35 , indicating strong intermolecular interactions between PVBT and PVBA. Accordingly, we conclude that these strong intermolecular interactions were directly responsible for the increases in the values of $T_{\mathrm{g}}$, because the degrees of polymerization of PVBT and PVBA were identical (i.e., the only change 
was the nature of the side chain group (nucleotide base)). This positive value of $q$ is not, however, particularly high when compared with those reported previously for $\mathrm{PVPh} / \mathrm{P} 4 \mathrm{VP}$ and $\mathrm{PVPh} / \mathrm{PVP}$ blends [7-15]. We suspect that the greater flexibility of the side chains in the homopolymers PVBT and PVBA, featuring $\mathrm{CH}_{2}$ groups from both the benzyl and propargyl units, decreased the value of $T_{\mathrm{g}}$ of the polymers.

Figure 7. (a) DSC curves and (b) glass transition temperature/composition curves, based on the Kwei equation, for PVBT/PVBA blend complexes of various compositions.
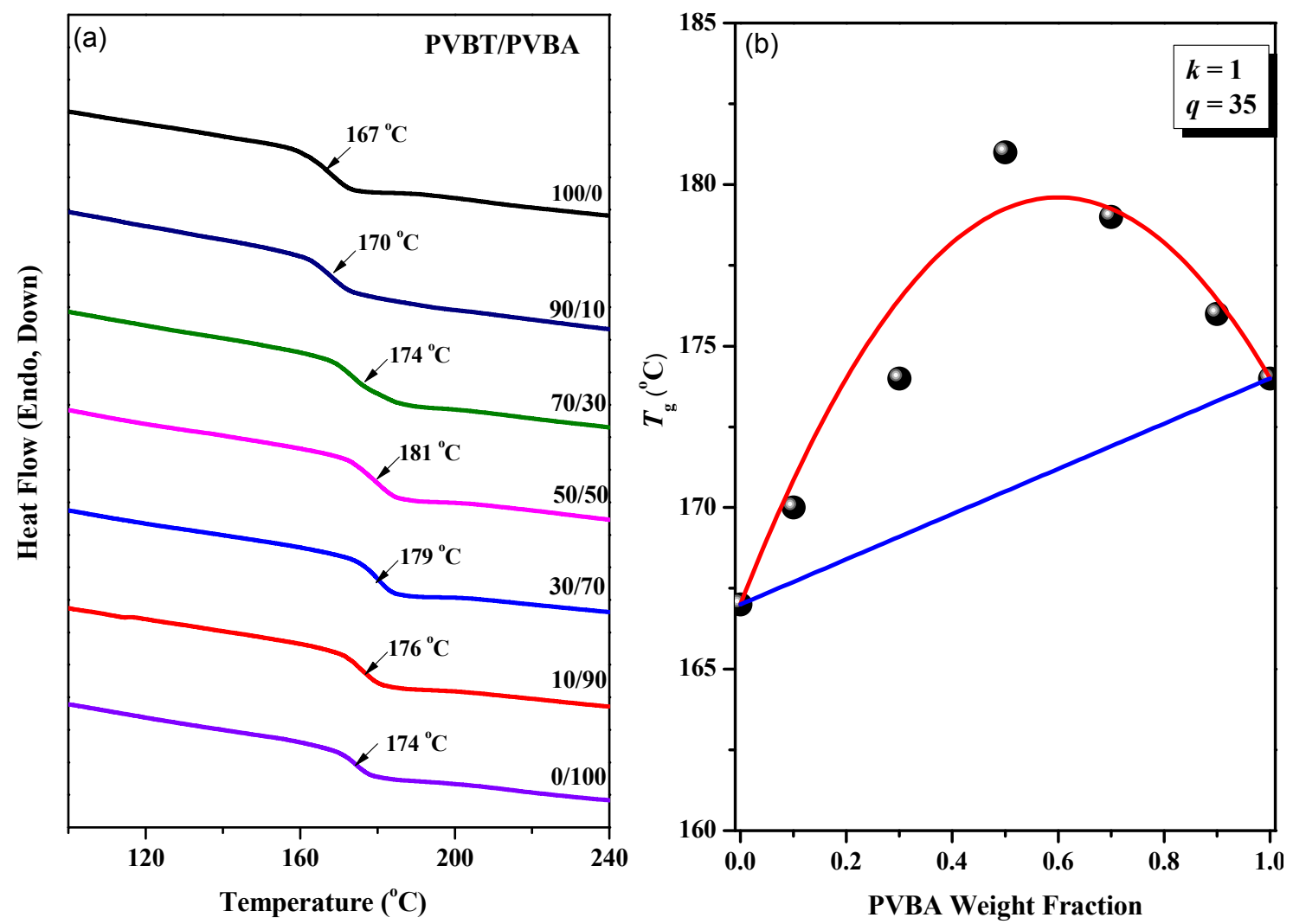

\subsection{Multiple Hydrogen Bonding Interactions in PVBT/PVBA Blend Complexes}

Infrared spectroscopy is a useful technique for investigating multiple hydrogen bonding interactions in supramolecular complexes. We used FTIR spectroscopy to confirm the presence of multiple hydrogen bonds between the nucleobase units of PVBT and PVBA. Figure 8a displays the room-temperature FTIR spectra of PVBT and PVBA, revealing a number of broad absorption bands in the region $3200-3600 \mathrm{~cm}^{-1}$, the $\mathrm{NH}$ stretching region. The band at $3454 \mathrm{~cm}^{-1}$ represents the stretching of free NH groups; this signal shifted to $3328 \mathrm{~cm}^{-1}$ for the A units interacting with the T units. In addition, a peak at $3200 \mathrm{~cm}^{-1}$ represents the $\mathrm{NH}$ groups in T units interacting with the A units [46].

The spectrum of pure PVBT (Figure $8 \mathrm{~b}$ ) features major peaks representing: (i) the free $\mathrm{C}_{2}=\mathrm{O}$ groups from the $\mathrm{T}$ units of PVBT $\left(1711 \mathrm{~cm}^{-1}\right)$; (ii) the free $\mathrm{C}_{4}=\mathrm{O}$ groups from the $\mathrm{T}$ units of PVBT (1680 $\left.\mathrm{cm}^{-1}\right)$; and (iii) the multiply hydrogen-bonded $\mathrm{C}_{4}=\mathrm{O}$ groups of the $\mathrm{T}$ units of PVBT $\left(1662 \mathrm{~cm}^{-1}\right)$ [48]. The characteristic signals for the A units of PVBA appeared at $1657 \mathrm{~cm}^{-1}$ (bonded $\mathrm{NH}_{2}$ scissor plus ring stretching) and $1600 \mathrm{~cm}^{-1}$ (ring stretching plus bonded $\mathrm{NH}_{2}$ scissor). The characteristic signals of the adenine groups of PVBA appeared at $1647 \mathrm{~cm}^{-1}$ (bonded $\mathrm{NH}_{2}$ scissor plus ring stretching) and 
$1596 \mathrm{~cm}^{-1}$ (ring stretching plus bonded $\mathrm{NH}_{2}$ scissor). The $\mathrm{C}=\mathrm{O}$ groups involved in the multiple hydrogen bonding interactions of $\mathrm{A}$ and $\mathrm{T}$ units were located in the range $1655-1665 \mathrm{~cm}^{-1}$, although the presence of many bands in this region made it difficult to calculate the area fraction of each peak. Thus, we focused only on the fractions of the free $\mathrm{C}=\mathrm{O}$ groups of the $\mathrm{T}$ units in the PVBT/PVBA complexes. For deconvolution, we fitted a series of Gaussian distributions to quantify the fraction of each of the peaks. The fraction of $\mathrm{C}_{2}=\mathrm{O}$ groups from the $\mathrm{T}$ units of PVBT decreased upon increasing the PVBA content; for example, the fraction of free $\mathrm{C}_{2}=\mathrm{O}$ groups for pure PVBT $(0.33)$ decreased to 0.14 for PVBT/PVBA $=10 / 90$ (Figure $8 \mathrm{~b}$ ), consistent with the existence of multiple hydrogen bonding interactions between the A and T groups in the PVBT/PVBA complexes.

Figure 8. FTIR spectra of various PVBT/PVBA blend complexes in the regions (a) $4000-2700 \mathrm{~cm}^{-1}$ and (b) $1800-1550 \mathrm{~cm}^{-1}$.

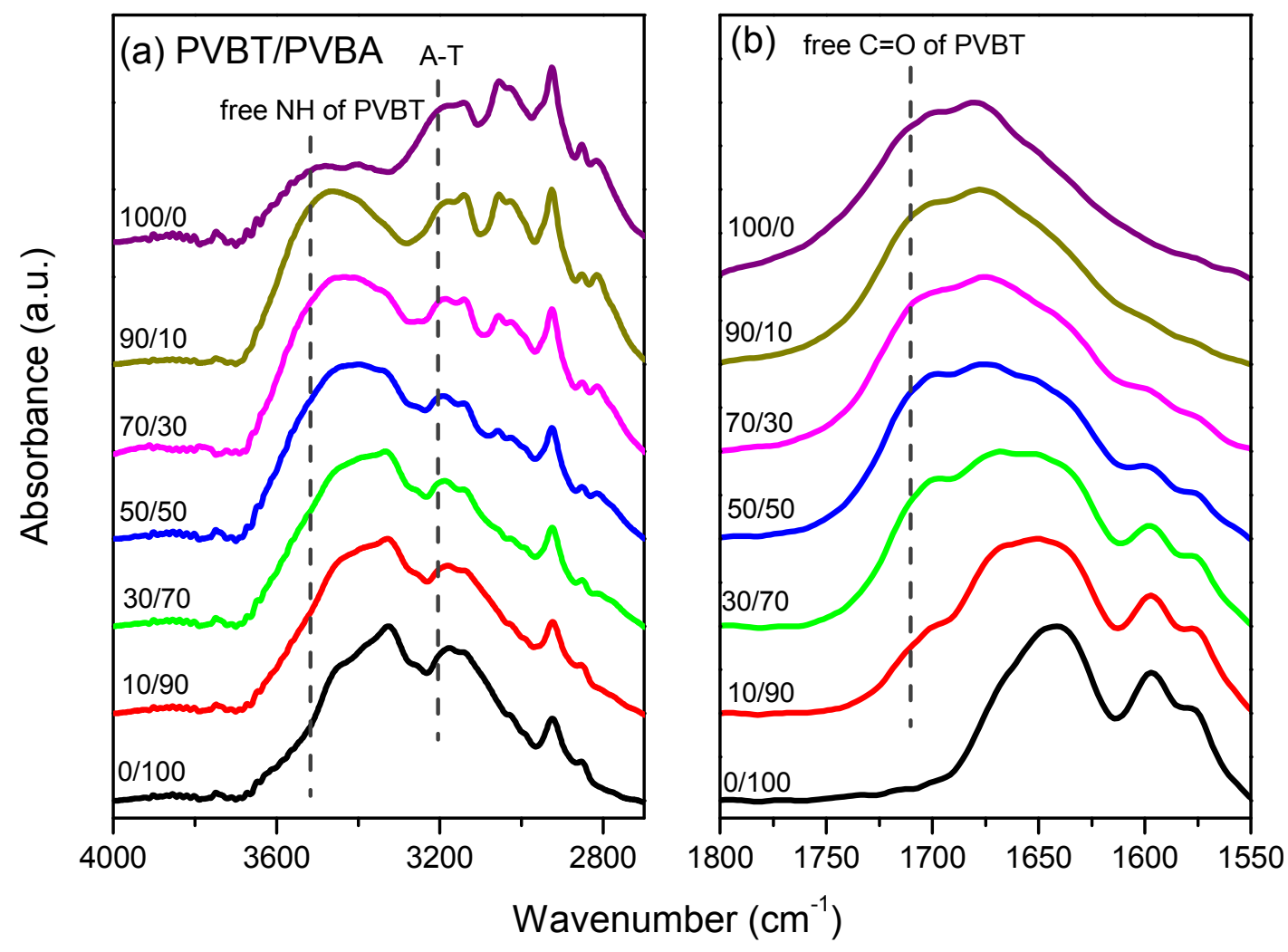

Because the homopolymers PVBT and PVBA are not soluble in $\mathrm{CDCl}_{3}$, we modeled their hydrogen bonding interactions by recording the ${ }^{1} \mathrm{H}$ NMR spectra of their monomers, VBT and VBA, respectively, in this solvent (Figure 9). The addition of VBA to a solution of VBT led to a significant downfield shift of the $\mathrm{NH}$ signal of the T group, initially at $8.91 \mathrm{ppm}$, to $11.88 \mathrm{ppm}$ at $70 \mathrm{wt} \% \mathrm{VBA}$, consistent with multiple intermolecular hydrogen bonds between the $\mathrm{T}$ and $\mathrm{A}$ groups. In a previous study [21], we calculated the inter-association equilibrium constant $\left(K_{\mathrm{a}}=534 \mathrm{M}^{-1}\right)$ between $\mathrm{T}$ and $\mathrm{A}$ groups through ${ }^{1} \mathrm{H}$ NMR spectroscopic titration of two low-molecular-weight model in $\mathrm{CDCl}_{3}$ at room temperature, based on the method developed by Benesi and Hildebrand [21]. In this present study, our samples of pure PVBT and PVBA dissolved only in highly polar solvents, such as DMF and DMSO; therefore, the changes in chemical shift and the inter-association equilibrium constant would be smaller than those obtained from $\mathrm{CDCl}_{3}$ solutions. 
Figure 9. ${ }^{1} \mathrm{H}$ NMR spectra displaying the chemical shift of the NH groups of VBT/VBA mixtures of various compositions.

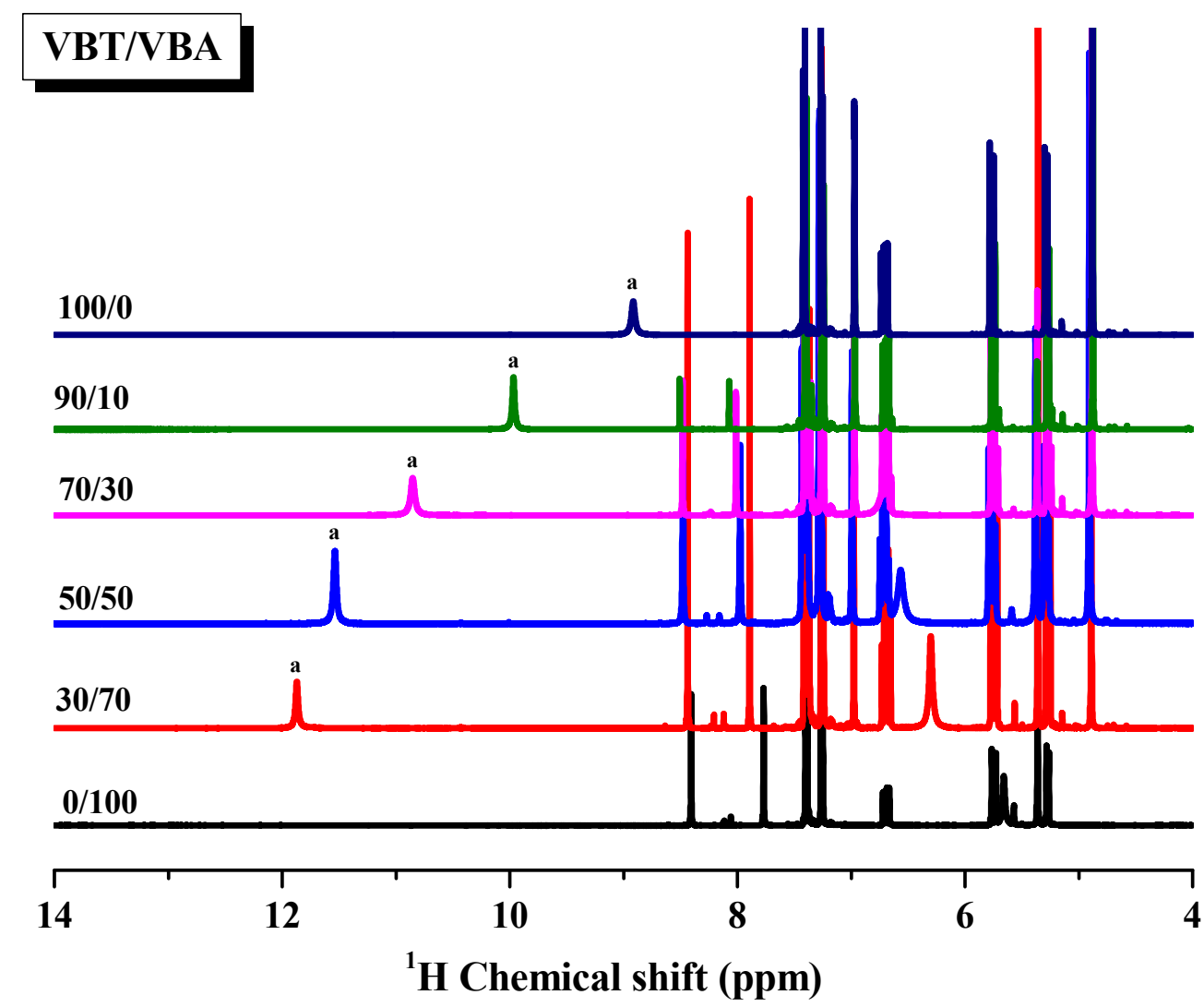

\subsection{Viscosity, DLS, TEM and AFM Analyses of Supramolecular Structures of PVBT/PVBA Complexes}

Figure 10 displays the viscosity curves for PVBT, PVBA and PVBT/PVBA complexes at various angular frequencies. The viscosity of the PVBT/PVBA complex was higher than those of pure PVBT and pure PVBA, because strong complementary multiple hydrogen bonding resulted in physical crosslinking. We also used DLS to characterize the supramolecular structures formed from the PVBT/PVBA mixtures in DMF; we analyzed the experimental correlation function using the cumulant method and the CONTIN algorithm, as described previously [21], and employed the Stokes-Einstein approximation to convert the diffusion coefficient into the hydrodynamic diameter $\left(D_{\mathrm{h}}\right)$.

Figure 11 reveals that the dependence of the hydrogen bonding interactions on the PVBT/PVBA mixture was complicated; we could discern, however, that the hydrodynamic diameter for the PVBT/PVBA complex was less than those of pure PVBT and pure PVBT. In general, individual polymer chains assemble together to form larger species. We suspect that the aggregated PVBT/PVBA chains collapsed, stabilized through complementary multiple hydrogen bonds between the $\mathrm{T}$ groups of PVBT and the A groups of PVBA, thereby decreasing the size of the aggregate in DMF solution. TEM is a good technique for observing local structures in real-space images at high resolution; it has been a powerful and efficient tool for determining the internal microstructures of polymeric micelles and nanoparticles $[49,50]$. Nevertheless, it can be difficult to observe core/shell structures using TEM if there is insufficient natural contrast between the core and shell components. In this study, however, we were able to use TEM in conjunction with staining techniques to directly explore the core/shell 
structures of PVBT/PVBA micelles in DMF solution. Because T and A units can be stained selectively by $\mathrm{I}_{2}$, we performed staining of the micelles prior to TEM observation [26]. Figure 12 displays the micrographs obtained for PVBT/PVBA mixtures of various ratios, after staining with $\mathrm{I}_{2}$ vapor for 90 min. We observe clear core/shell micelle structures for PVBT/PVBA $=50 / 50$, as revealed in Figure $12 \mathrm{c}, \mathrm{d}$, with all of the nanoparticles featuring dark cores, arising from the multiply hydrogen bonding A-T groups, surrounded by less-dense shells (polystyrene main chains), as displayed in Scheme 2. The contrast between the shells and the halo-shells was intensified through staining of the PVBT and PVBA chains. A relatively clear boundary existed between each core and shell, as a result of the complementary A-T multiple hydrogen bonding. Because we prepared the samples for TEM observation through the evaporation of dilute micelle solutions on grids, we could not avoid the aggregation of the micelle particles, chain collapse or micelle deformation [51]. Therefore, the sizes and size distributions of the micelles determined from TEM analysis (ca. 200-250 nm) are smaller than the DLS data ( $c$. 225-300 nm) for PVBT/PVBA = 30/70, 50/50 and 70/30. In addition, multiple complementary hydrogen bonds are sensitive to the variation of environments, such as temperature and solvents, which will be discussed in our further study [52-54].

Figure 10. Apparent viscosities of (a) PVBT; (b) PVBA; and (c) the PVBT/PVBA $=50 / 50$ blend complex.

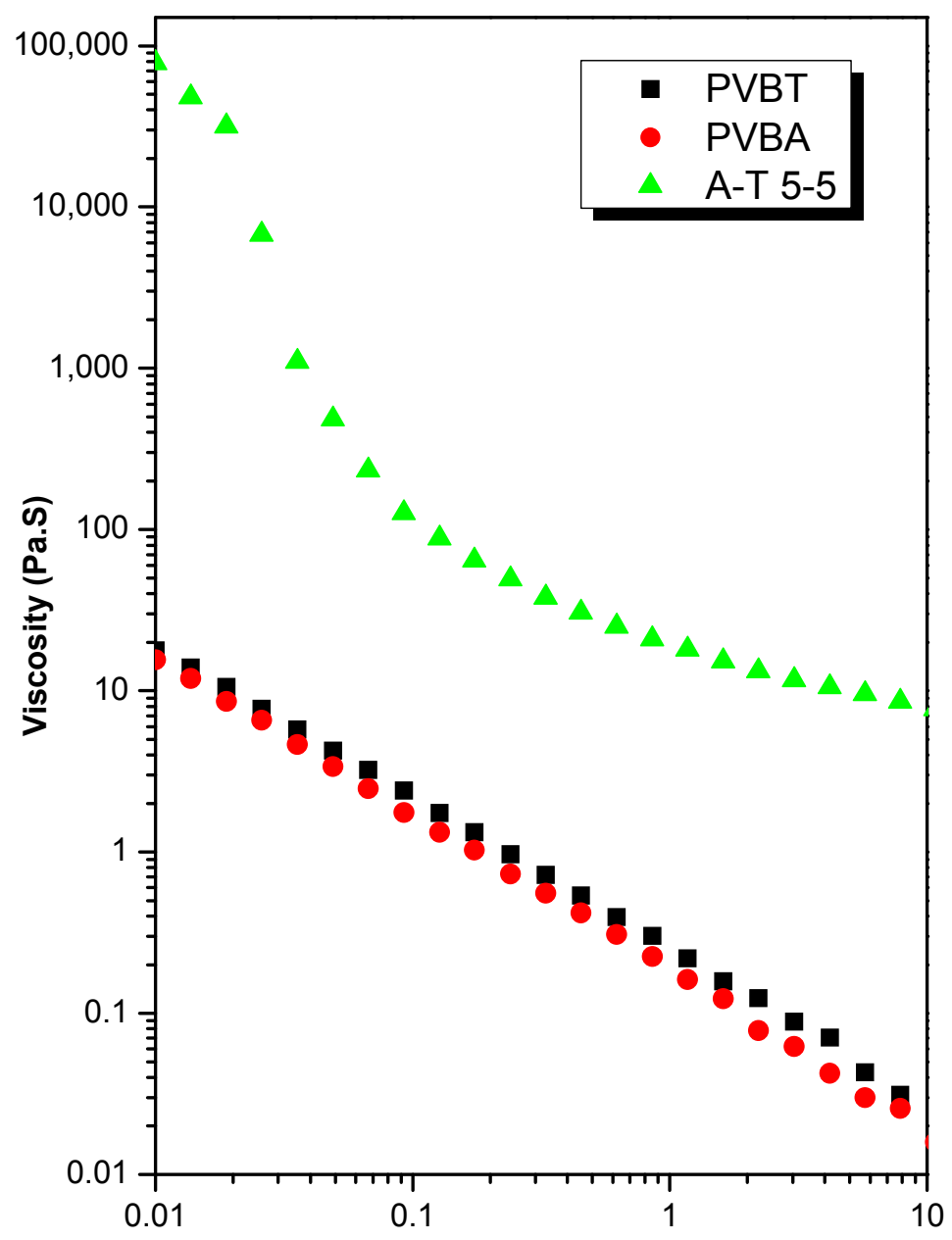

Angular Frequency (1/s) 
Figure 11. Hydrodynamic radius distributions of PVBT/PVBA blend complexes of various compositions.

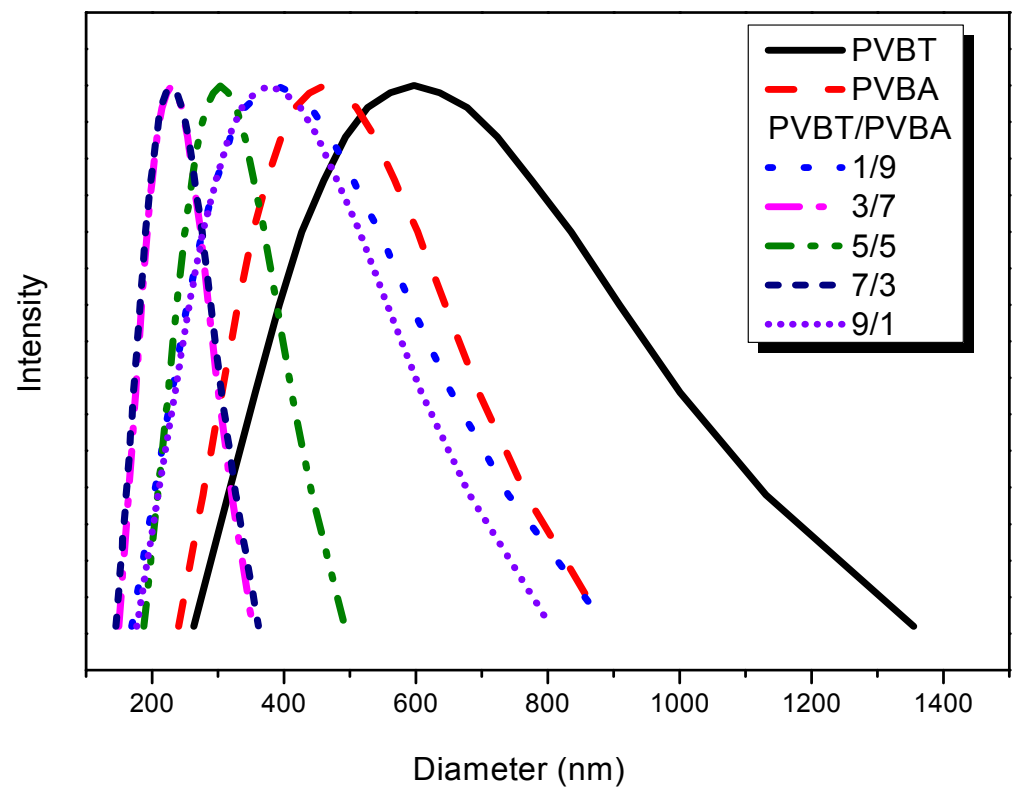

Figure 12. TEM images of PVBT/PVBA blend complexes in DMF solution: (a) 10/90; (b) 30/70; (c,d) 50/50; (e) 70/30; and (f) 90/10.
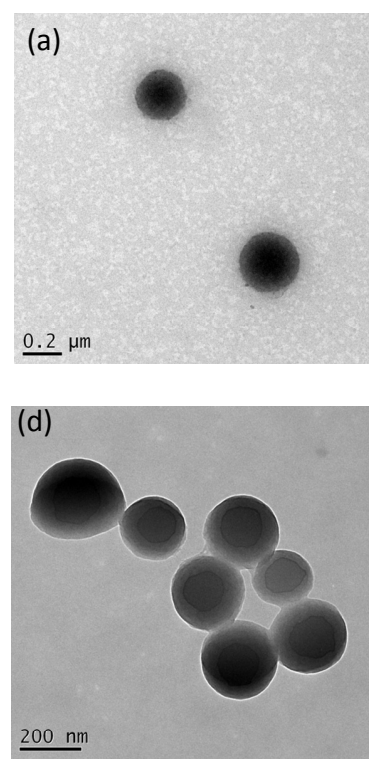
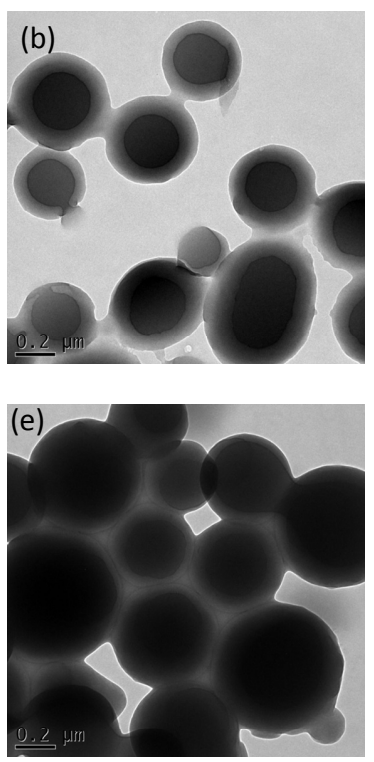
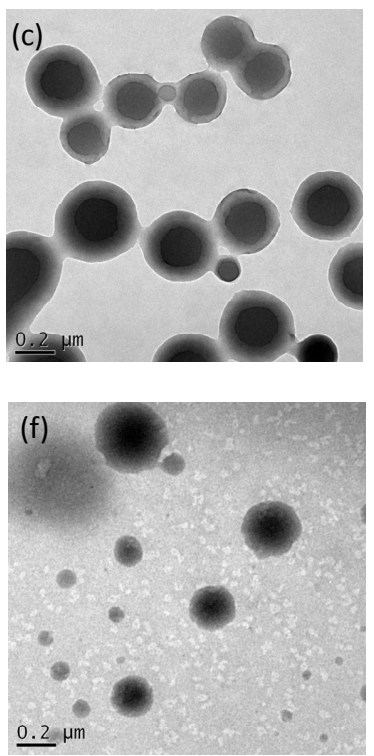

Scheme 2. Cartoon representation of the aggregation of a PVBT/PVBA blend complex.
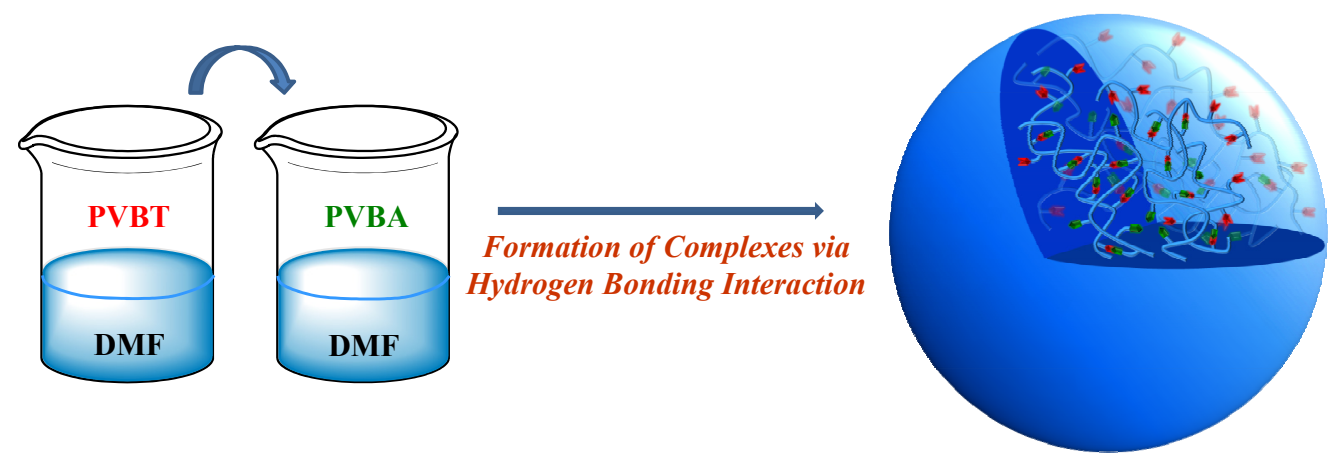


\section{Conclusions}

We have used a combination of NMRP and click chemistry to synthesize T- and A-containing homopolymers of the same molecular weight. Blends of this PVBT/PVBA complex system exhibited a single glass transition temperature over the entire composition range, indicating that they formed a miscible phase stabilized through strong complementary multiple hydrogen bonding between their $\mathrm{T}$ and A groups. DSC, dynamic rheology, DLS and TEM analyses confirmed the high thermal stability, high viscosity and supramolecular network structures of these complexes.

\section{Acknowledgments}

This study was supported financially by the National Science Council, Taiwan, Republic of China, under contracts NSC 100-2221-E-110-029-MY3 and NSC 102-2221-E-110-008-MY3. We thank Hsien-Tsan Lin of the Regional Instruments Center at National Sun Yat-Sen University for help with the TEM experiments.

\section{Author Contributions}

$\mathrm{Yu}$-Shian $\mathrm{Wu}$ contributed to the analysis of the data and writing of the paper. Yi-Chen $\mathrm{Wu}$ synthesizes the TEMPO compound, PVBC, $\mathrm{PVBN}_{3}$, PVBT and carried out the analyses. Shiao-Wei Kuo coordinated the study, interpreted the results and discussion and contributed to the writing of the paper.

\section{Conflicts of Interest}

The authors declare no conflict of interest.

\section{References}

1. Coleman, M.M.; Painter, P.C. Hydrogen bonded polymer blends. Prog. Polym. Sci. 1995, 20, 1-59.

2. He, Y.; Zhu, B.; Inoue, Y. Hydrogen bonds in polymer blends. Prog. Polym. Sci. 2004, 29, 1021-1051.

3. Kuo, S.W. Hydrogen-bonding in polymer blends. J. Polym. Res. 2008, 15, 459-486.

4. Kuo, S.W.; Chan, S.C.; Chang, F.C. Effect of hydrogen bonding strength on the microstructure and crystallization behavior of crystalline polymer blends. Macromolecules 2003, 36, 6653-6661.

5. Coleman, M.M.; Graf, J.F.; Painter, P.C. Specific Interactions and the Miscibility of Polymer Blends; Technomic Publishing: Lancaster, PA, USA, 1991.

6. Kuo, S.W.; Chen, C.J. Using hydrogen-bonding interactions to control the peptide secondary structures and miscibility behavior of poly(L-glutamate)s with phenolic resin. Macromolecules 2011, 44, 7315-7326.

7. De Mefathi, M.V.; Frechet, J.M.J. Study of the compatibility of blends of polymers and copolymers containing styrene, 4-hydroxystyrene and 4-vinylpyridine. Polymer 1988, 29, 477-482.

8. Xiang, M.; Jiang, M.; Zhang, Y.; Wu, C. Intermacromolecular complexation due to specific interactions 4. The hydrogen-bonding complex of vinylphenol-containing copolymer and vinylpyridine-containing copolymer. Macromolecules 1997, 30, 2313-2319. 
9. Wang, J.; Cheung, M.K.; Mi, Y. Miscibility in blends of poly(4-vinylpyridine)/ poly(4-vinylphenol) as studied by ${ }^{13} \mathrm{C}$ solid-state NMR. Polymer 2001, 42, 3087-3093.

10. Kuo, S.W.; Chang, F.C. Studies of miscibility behavior and hydrogen bonding in blends of poly(vinylphenol) and poly(vinylpyrrolidone). Macromolecules 2001, 34, 5224-5228.

11. Kuo, S.W.; Tung, P.H.; Chang, F.C. Syntheses and the study of strongly hydrogen-bonded poly(vinylphenol-b-vinylpyridine) diblock copolymer through anionic polymerization. Macromolecules 2006, 39, 9388-9395.

12. Wang, M.; Jiang, M.; Ning, F.L.; Chen, D.Y.; Liu, S.Y.; Duan, H.W. Block-copolymer-free strategy for preparing micelles and hollow spheres:self-assembly of poly(4-vinylpyridine) and modified polystyrene. Macromolecules 2002, 35, 5980-5989.

13. Chen, W.C.; Kuo, S.W.; Jeng, U.S.; Chang, F.C. Self-assembly through competitive interactions of miscible diblock copolymer/homopolymer blends: Poly(vinylphenol-b-methyl methacrylate)/ poly(vinylpyrrolidone) blend. Macromolecules 2008, 41, 1401-1410.

14. Chen, W.C.; Kuo, S.W.; Lu, C.H.; Jeng, U.S.; Chang, F.C. Self-assembly structures through competitive interactions of crystalline-amorphous diblock copolymer/homopolymer blends: Poly(e-caprolactone- $b$-4-vinyl pyridine)/poly(vinyl phenol). Macromolecules 2009, 42, 3580-3590.

15. Chen, W.C.; Kuo, S.W.; Chang, F.C. Self-assembly of an A-B diblock copolymer blended with a $\mathrm{C}$ homopolymer and a $\mathrm{C}-\mathrm{D}$ diblock copolymer through hydrogen bonding interaction. Polymer 2010, 51, 4176-4184.

16. IIhan, F.; Gray, M.; Rotello, V.M. Reversible side chain modification through noncovalent interactions: "plug and play" polymers. Macromolecules 2001, 34, 2597-2601.

17. Sherrington, D.C.; Taskinen, K.A. Self-assembly in synthetic macromolecular systems via multiple hydrogen bonding interactions. Chem. Soc. Rev. 2001, 30, 83-93.

18. Feldman, K.E.; Kade, M.J.; de Greef, T.F.A.; Meijer, E.W.; Kramer, E.J.; Hawker, C.J. Polymers with multiple hydrogen-bonded end groups and their blends. Macromolecules 2008, 41, 4694-4700.

19. Sivakava, S.; Wu, J.; Campo, C.J.; Mather, P.T.; Rowan, S.J. Liquid-crystalline supramolecular polymers formed through complementary nucleobase-pair interactions. Chem. A Eur. J. 2005, 12, 446-456.

20. Altintas, O.; Schulze-Suenninghausen, D.; Luy, B.; Barner-Kowollik, C. Facile preparation of supramolecular H-shaped (Ter)polymers via multiple hydrogen bonding. ACS Macro Lett. 2013, 2, 211-216.

21. Kuo, S.W.; Cheng, R.S. DNA-Like interactions enhance the miscibility of supramolecular polymer blends. Polymer 2009, 50, 177-188.

22. Kuo, S.W.; Tsai, H.T. Complementary multiple hydrogen-bonding interactions increase the glass transition temperatures to PMMA copolymer mixtures. Macromolecules 2009, 42, 4701-4711.

23. Kuo, S.W.; Hsu, C.H. Miscibility enhancement of supramolecular polymer blends through complementary multiple hydrogen bonding interactions. Polym. Int. 2010, 59, 998-1005.

24. Kuo, S.W.; Tsai, H.T. Self-complementary multiple hydrogen bonding interactions increase the glass transition temperatures to supramolecular poly(methyl methacrylate) copolymers. J. Appl. Polym. Sci. 2012, 123, 3275-3282. 
25. Hu, W.H.; Huang, K.W.; Kuo, S.W. Heteronucleobase-functionalized benzoxazine: Synthesis, thermal property and multiple hydrogen bonding interactions. Polym. Chem. 2012, 3, 1546-1554.

26. Wu, Y.C.; Kuo, S.W. Complementary multiple hydrogen bonding interactions mediate the self-assembly of supramolecular structures from thymine-containing block copolymers and hexadecyladenine. Polym. Chem. 2012, 3, 3100-3111.

27. Wang, J.H.; Altukhov, O.; Cheng, C.C.; Chang, F.C.; Kuo, S.W. Supramolecular structures of uracil-functionalized PEG with multi-diamidopyridine POSS through complementary hydrogen bonding interactions. Soft Matter 2013, 9, 5196-5206.

28. Huang, K.W.; Wu, Y.R.; Kuo, S.W. From random coil to helical structure induced by carbon nanotube through supramolecular interactions. Macromolecules Rapid Commun. 2013, 34, 1530-1536.

29. Park, T.; Zimmerman, S.C. Formation of a miscible supramolecular polymer blend through self-assembly mediated by a quadruply hydrogen-bonded heterocomplex. J. Am. Chem. Soc. 2006, 128, 11582-11590.

30. Mather, B.D.; Baker, M.B.; Beyer, F.L.; Berg, M.A.G.; Green, M.D.; Long, T.E. Supramolecular triblock copolymers containing complementary nucleobase nolecular recognition. Macromolecules 2007, 40, 6834-6845.

31. Nair, K.P.; Breedveld, V.; Weck, M. Complementary hydrogen-bonded thermoreversible polymer networks with tunable properties. Macromolecules 2008, 41, 3429-3438.

32. Mather, B.D.; Lizotte, J.R.; Long, T.E. Synthesis of chain end functionalized multiple hydrogen bonded polystyrenes and poly(alkyl acrylates) using controlled radical polymerization. Macromolecules 2004, 37, 9331-9337.

33. Bazzi, H.S.; Sleiman, H.F. Adenine-containing block copolymers via ring-opening metathesis polymerization: synthesis and self-assembly into rod morphologies. Macromolecules 2002, 35, 9617-9620.

34. Park, T.; Zimmerman, S.C. Interplay of fidelity, binding strength, and structure in supramolecular polymers. J. Am. Chem. Soc. 2006, 128, 14236-14237.

35. Smith, J.R.; Walter, T. Nucleic acid models. Prog. Polym. Sci. 1996, 21, 209-253.

36. Watson, J.D.; Berry, A. DNA: The Secret of Life; Knopf: New York, NY, USA, 2003.

37. Lutz, J.F.; Thunemann, A.F.; Rurack, K. DNA-like "melting" of adenine- and thymine-tunctionalized synthetic copolymers. Macromolecules 2005, 38, 8124-8126.

38. Lutz, J.F.; Thunemann, A.F.; Nehbring, R. Preparation by controlled radical polymerization and self-assembly via base-recognition of synthetic polymers bearing complementary nucleobases. J. Polym. Sci. Polym. Chem. 2005, 43, 4805-4818.

39. Lutz, J.F.; Pfeifer, S.; Chanana, M.; Thunemann, A.F.; Bienert, R. H-Bonding-directed self-assembly of synthetic copolymers containing nucleobases: organization and colloidal fusion in a noncompetitive solvent. Langmuir 2006, 22, 7411-7415.

40. Yamauchi, K.; Kanomata, A.; Inoue, T.; Long, T.E. Thermoreversible polyesters consisting of multiple hydrogen bonding (MHB). Macromolecules 2004, 37, 3519-3522.

41. Odian, G. Principles of Polymerization; Wiley Publication: New York, NY, USA, 1991; p. 470.

42. Overberger, C.C.; Inaki, Y. Graft copolymers containing nucleic acid bases and L-amino acids. J. Polym. Sci. Polym. Chem. Ed. 1979, 17, 1739-1958. 
43. Inaki, Y.; Sakuma, Y.; Suda, Y.; Takemoto, K. Functional monomers and polymers. XCVII. Synthesis of oligomer models of polyethyleneimine derivatives containing pendant thymine bases. J. Polym. Sci. Polym. Chem. Ed. 1982, 20, 1917-1933.

44. Cheng, C.C.; Huang, C.F.; Yen, Y.C.; Chang, F.C. A "plug and play" polymer through biocomplementary hydrogen bonding. J. Polym. Sci. A Polym. Chem. 2008, 46, 6416-6424.

45. Lu, C.H.; Huang, C.F.; Kuo, S.W.; Chang, F.C. Synthesis and characterization of poly( $\varepsilon$-caprolactone- $b$-4-vinylpyridine): Initiation, polymerization, solution morphology, and gold metalation. Macromolecules 2009, 42, 1067-1078.

46. Wu, Y.C.; Kuo, S.W. Self-Assembly supramolecular structure through complementary multiple hydrogen bonding of heteronucleobase-multifunctionalized polyhedral oligomeric silsesquioxane (POSS) complexes. J. Mater. Chem. 2012, 22, 2982-2991.

47. Kwei, T. The effect of hydrogen bonding on the glass transition temperatures of polymer mixtures. J. Polym. Sci. Polym. Lett. Ed. 1984, 22, 307-313.

48. Wang, J.H.; Altukhov, O.; Cheng, C.C.; Chang, F.C.; Kuo, S.W. Investigating the Effect of Uracil-Functionalized Poly(ethylene glycol) on the Thermal Properties, Interactions, and Conductivity Behavior with $\mathrm{LiAsF}_{6}$ Salt. Polymers 2013, 5, 937-953.

49. Zhang, L.; Eisenberg, A. Multiple morphologies of "Crew-Cut" aggregates of polystyrene- $b$-poly(acrylic acid) block copolymers. Science 1995, 268, 1728-1731.

50. Wang, X.; Chen, J.; Hong, K.; Mays, J.W. Well-defined polyisoprene- $b$-poly(acrylic acid)/polystyrene- $b$-polyisoprene- $b$-poly(acrylic acid) block copolymers: synthesis and their self-assembled hierarchical structures in aqueous media. ACS Macro Lett. 2012, 1, 743-747.

51. Guo, M.; Jiang, M. Non-covalently connected micelles (NCCMs): The origins and development of a new concept. Soft Matter 2009, 5, 495-500.

52. Wang, D.; Su, Y.; Jin, C.; Zhu, B.; Pan, Y.; Zhu, L.; Liu, J.; Tu, C.; Yan, D.; Zhu, X. Supramolecular copolymer micelles based on the complementary multiple hydrogen bonds of nucleobases for drug delivery. Biomacromolecules 2011, 12, 1370-1379.

53. Wang, D.; Huan, X.; Zhu, L.; Liu, J.; Qiu, F.; Yan, D.; Zhu, X. Salt/pH dual-responsive supramolecular brush copolymer micelles with molecular recognition of nucleobases for drug delivery. RSC Adv. 2012, 2, 11953-11962.

54. Wang, D.; Chen, H.; Su, Y.; Qiu, F.; Zhu, L.; Huan, X.; Zhu, B.; Yan, D.; Guo, F.; Zhu, X. Supramolecular amphiphilic multiarm hyperbranched copolymer: Synthesis, self-assembly and drug delivery applications. Polym. Chem. 2013, 4, 85-94.

(C) 2014 by the authors; licensee MDPI, Basel, Switzerland. This article is an open access article distributed under the terms and conditions of the Creative Commons Attribution license (http://creativecommons.org/licenses/by/3.0/). 